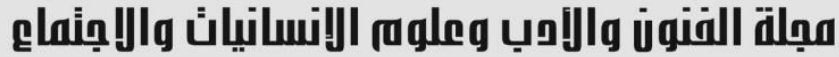

Journal of Arts, Literature, Humanities and Social Sciences www.jalhss.com

\section{أثر التظيم القانوني للتغيرات البيئية على الاقتصاد}

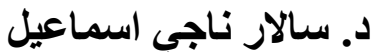 \\ دكتوراه في القانون العام ـ الاقتصاد والعادي المالية العامة

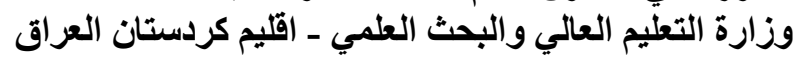 \\ البريد الاكتروني: yahoo.com
}

هناك تغيرات بيئية تحدث يومياً حولنا، و هي تؤثر في المجتمع، وكذلك يؤثر المجتمع في حدوثها، ومن خلال هذه البحث؛ سيتم البحث عن الإطار العام للبيئة ، وما يحدث فيها من تغيرات تؤثر على شتى المجالات بـالمجتمع، ثم سنقوم بالبحث عن كيفية الحماية القانو نية لتلك التغير ات وتحجيمها عن طريق التشريع، وبعد ذللك نعرض للآثار و النتائج التي تحدث عن تلك التغيرات البيئية، وخاصةً الآثار الاقتصادية التي تتنج عن تلك الحماية القانونية . فالاقتصاد يدخل في جميع مجالات المجتمع، سواء كانت علمية وطبية أم سياسية أم تشريعية، وما إلى ذلك من الججالات، لذا كان ضرورياً مناقتنة البيئة و الجينات من الناحية الاقتصادية لنعرف العلاقة فيما بين "علم البيئة و الهندسة الور اثية للنطور ات الجينية "و " التشريع الاقتصادي ". 


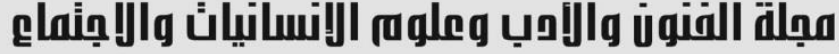

Journal of Arts, Literature, Humanities and Social Sciences

www.jalhss.com

Volume (68) June 2021

العدد (68) يونيو 2021

\section{The Impact of Legal Regulation of Environmental Changes on the Economy}

\author{
Dr. Salar Naji Ismael \\ PhD in Public Law - Economics and Public Finance \\ Ministry of Higher Education and Scientific Research - Kurdistan Region of Iraq \\ Email: Phisyo2003@yahoo.com
}

\begin{abstract}
There are environmental changes that occur daily around us' and they affect society، as well as society affects their occurrence، and through this research; A search will be made for the general framework of the environment، and the changes that occur in it that affect various areas of society، then we will search for how to legally protect these changes and scale them through legislation، and then we will present the effects and results that occur from these environmental changes، especially the economic effects that result from That legal protection.

The economy is included in all areas of society، whether scientific medical political، legislative، and so on. Therefore، it was necessary to discuss the environment and genetics from an economic point of view، in order to know the relationship between "ecology and genetic engineering of genetic developments" and "economic legislation".
\end{abstract}

Keywords: Legal Regulation, Environmental Changes, Economy. 


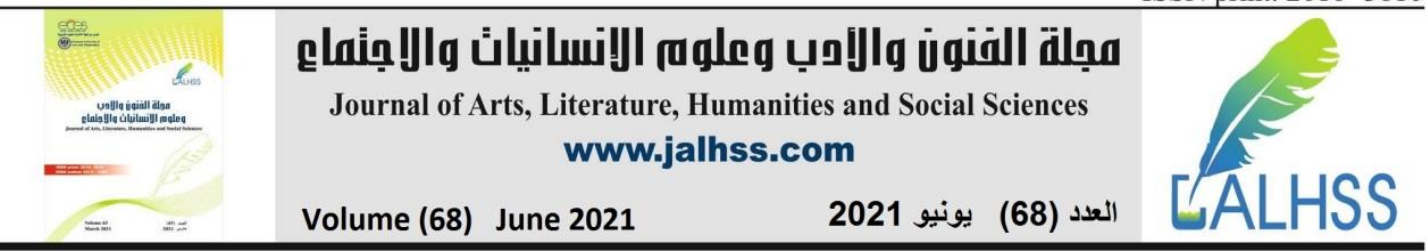

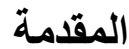

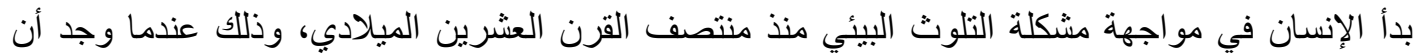

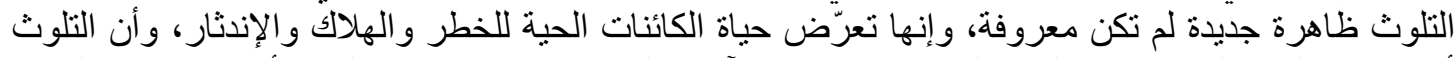

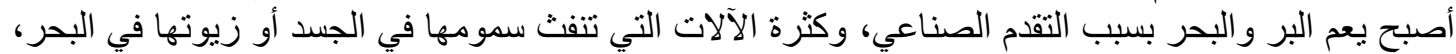

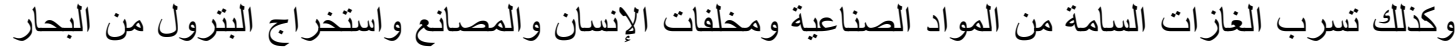

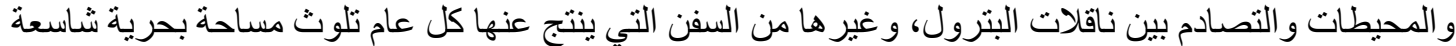

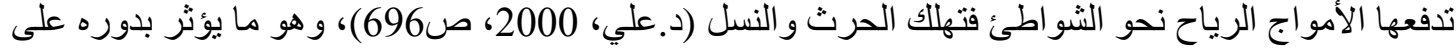

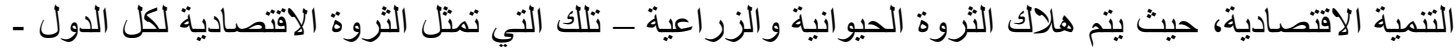

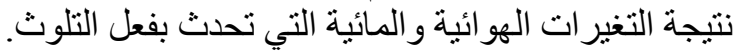
وهكذا أدت العلاقة السلبية بين الإنسان والبيئة في العصر العية العديث إلى الى ظهور طائفة من الظواهر البيئية

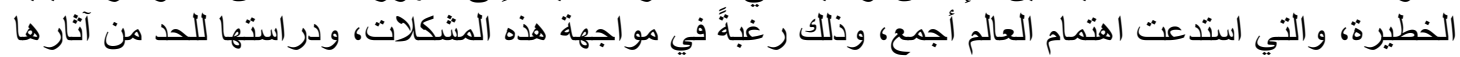

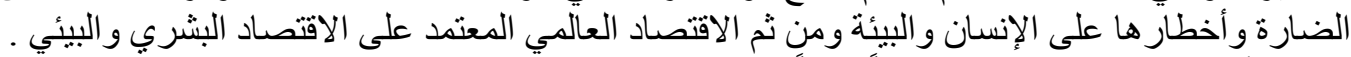

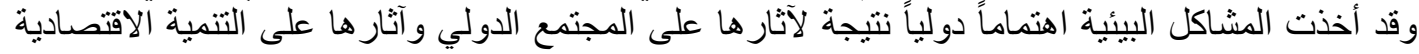

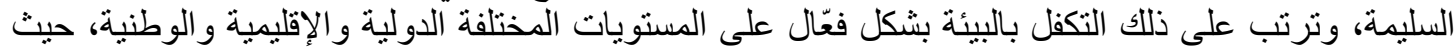

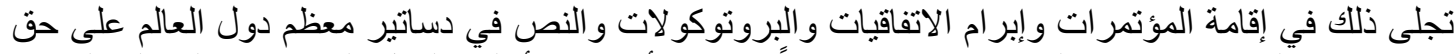

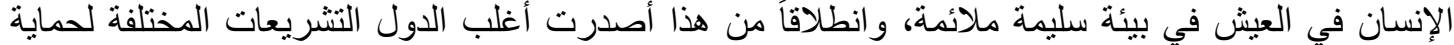

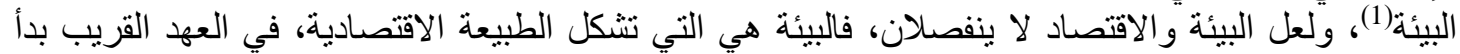

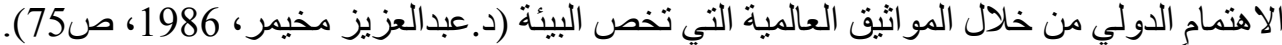

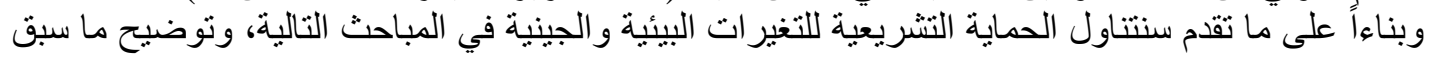
في إطار اقتصادي. المبحث الأول : الأثر الاقتصادي للحماية القانونية للتغير ات البيائية

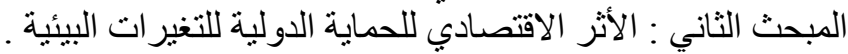

\section{المبحث الأول \\ الأثر الاقتصادي للحماية القانونية للتغيرات البيئية}

للتغييرات الجينية و البيئية آثار قد تكون خطيرة على البيئة ومن ثم الاقتصاد؛ لذا فالتأثير المتز ايد لأخطار

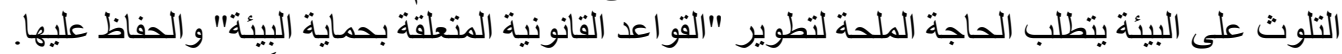

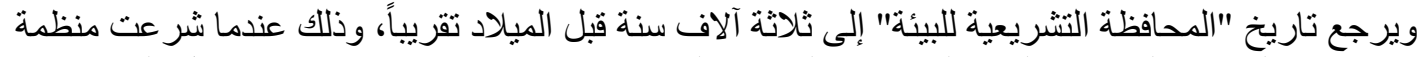

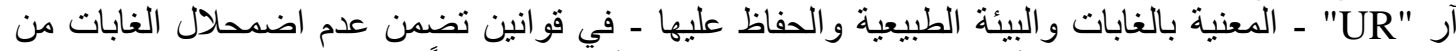
جر اء الإستنز اف الجائر ، وبالمثل أقر المجلس الروماني قبل نحو ألفي سنة قانوناً يقضي بحفظ المياه خلال فترات فترات

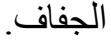

وفي ضوء الحماية القانونية للتغيرات الجينية والبيئية وما ينتج عنها من آثار اقتصادية على المجتمع؛ فإننا

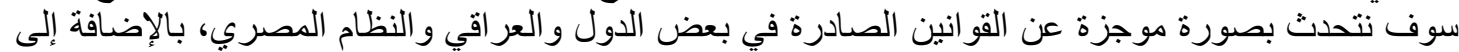

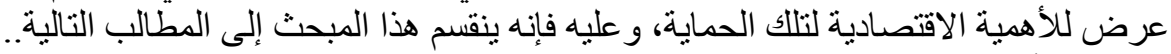

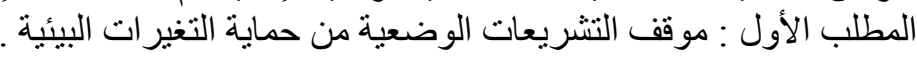
المطلب الثاني : التحليل الاقتصادي لتقنين التغيرات البيئية . 


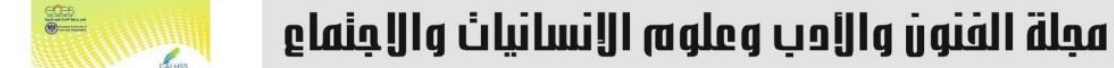 \\ Journal of Arts, Literature, Humanities and Social Sciences www.jalhss.com \\ Volume (68) June 2021 \\ العدد (68) يونيو 2021 \\ المطلب الأول \\ موقف التشريعات الوضعية من حماية التغير ات البيئية}

لم يكن المشرع العر اقي بعيداً عن هذه التغيرات، والتشريعات الوضعية المقارنة من حماية التغيرات البيئية

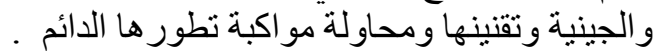

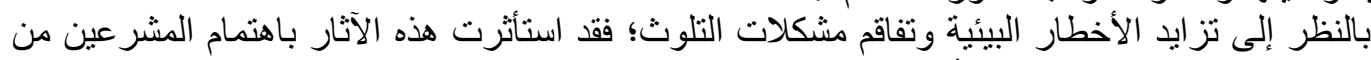

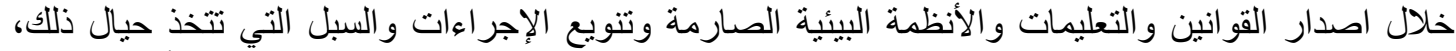

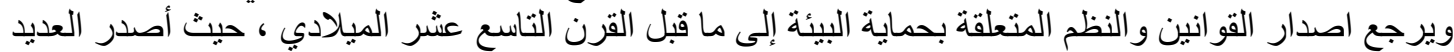

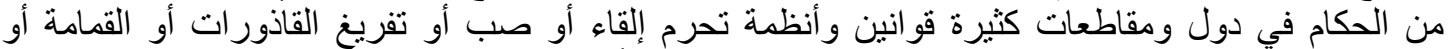

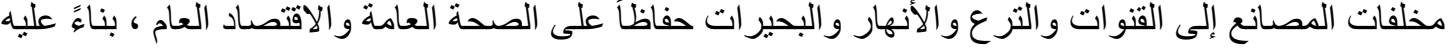

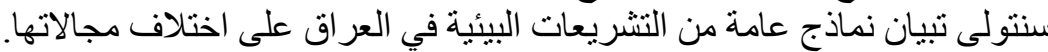

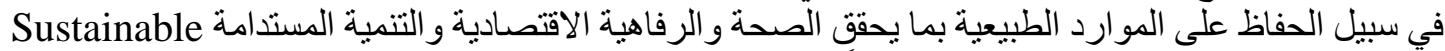

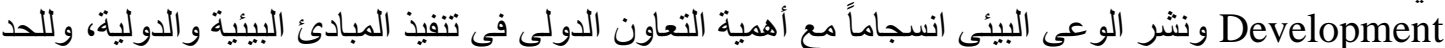

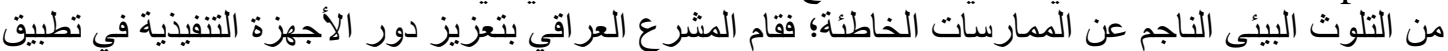

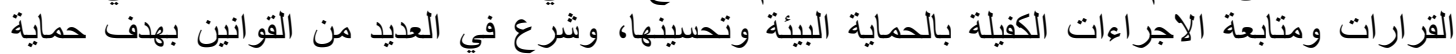

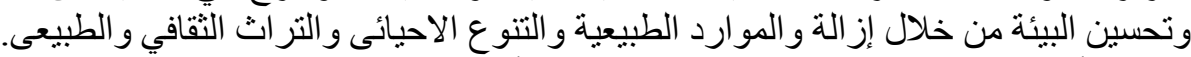

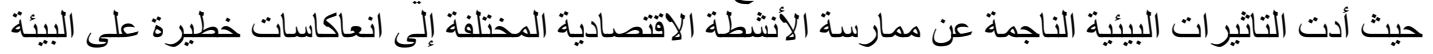

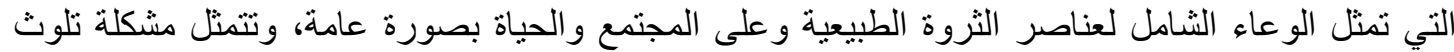

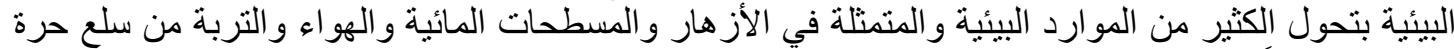

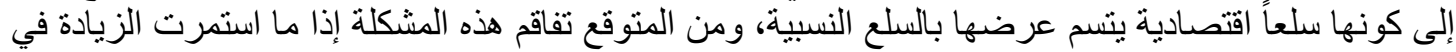

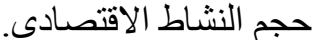
و الواضح أن التقام الاقتصادي يرافق زيادة التكاليف التي يلزم تحملها للإبقاء على البيئة نظيفة ويفرق الاقتصاديون بين "التكلفة الخاصة" والفي و "التكلفة الاجتماعية".

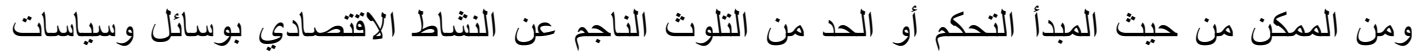

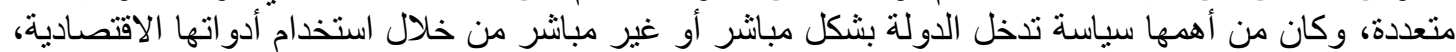

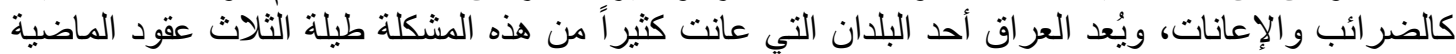

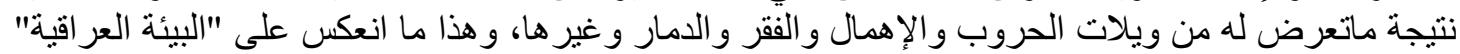

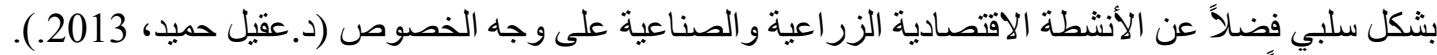

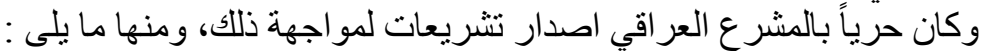

- قانون المو اد القابلة للإنفجار المعدني رقم 20 لسنة 1957. - قانون السلامة المهنية للوقاية من استخدام المو اد الكيمياوية والسامة رقم 11 لسنة 1964. - قانون صيانة الثروة النفطية والمو اد الهيدروكوربونية رقم 229 لسنة 1970 ـ 1970

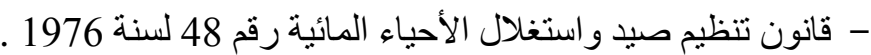
- قانون الجهاز المركزي للتقييس و السيطرة النو عية رقم 54 لسنة 1979 ـ 1982 ـ - قانون المؤسسة العامة للتصميم والانثاء الصناعي رقم 78 لسنة 1982 ـ

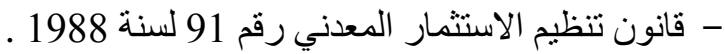

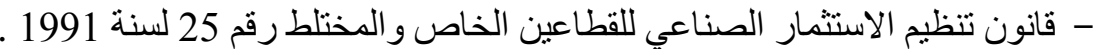

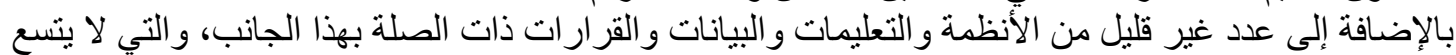

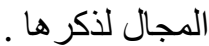

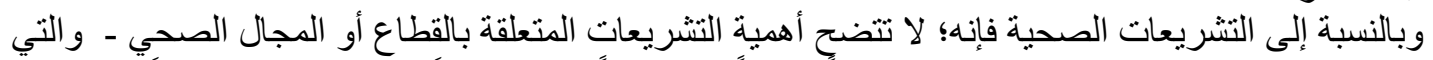

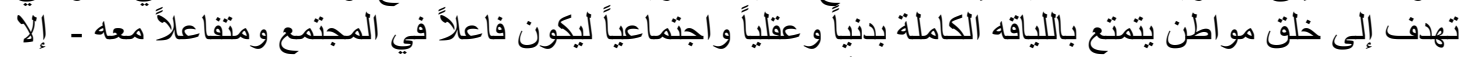

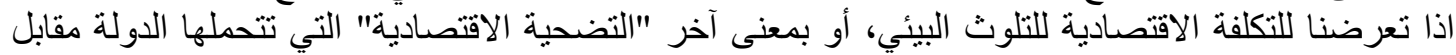




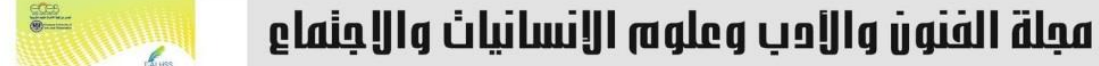 \\ Journal of Arts, Literature, Humanities and Social Sciences www.jalhss.com \\ Volume (68) June 2021 \\ العدد (68) يونيو 2021}

خدمة أو منفعة ضرورية لتحقيق أهدافها والكلفة البيئية، و التي تشمل كافة الإجراءات المتخذة لإز الة آثار البيئة

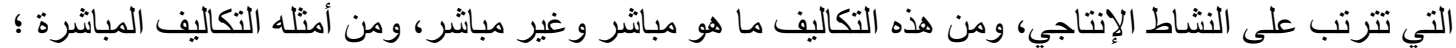

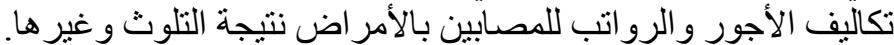
أما التكاليف غير المباثرة تتمثل في التكاليف التي تخدم مراحل الإنتاج ككل، ومنها: تكاليف الموالئ التهارد البيئية

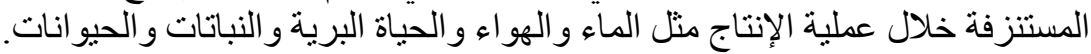

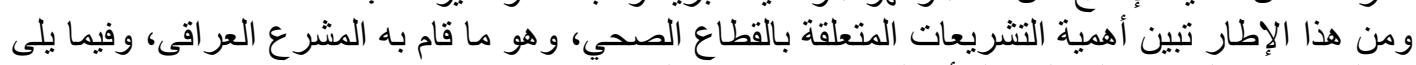

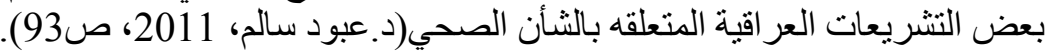
- قانون لجنة الطاقة الذرية رقم 1 لسنة 1959 ، للحماية من الآثار الناتجة عن سوء استغلاكل الطاقة الذرية.

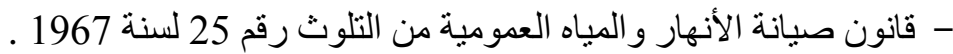
- قانون المو اصفة القياسية العر اقية لمياه الثرب رقياه رقم 417 لسنة 1974 ـ - قانون الحماية من الإشعاعات النووية رقم 99 لسنة 1980 ـ العائة - قانون إنشاء المركز الوطني للبحوث ومعالجة الأمر اض السرطانية الإنانية رقم 858 لسنة 1982 ـ - قانون منع السيارات الحوضية المحملة بالمشتقات النفطية من طرح مخلفاتها إلى المصادر المائية رقم 4 لسنة

- قانون منع تصريف مياه المجاري المنزلية أو العامة إلى الأنهار رقم 5 لسنة 1991 ـ - قانون حماية وتحسين البيئة رقم 76 لسنة 1986 ـ 1986

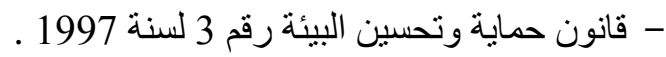

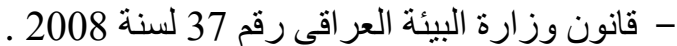

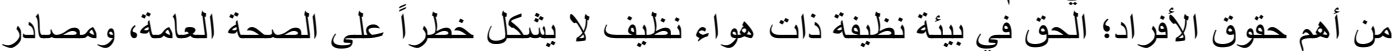

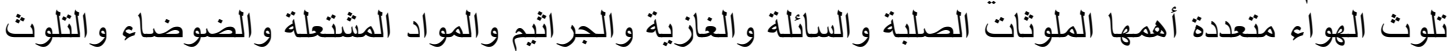

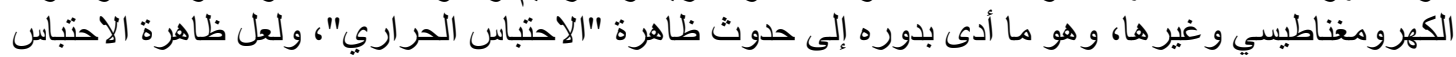

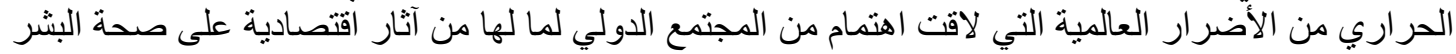

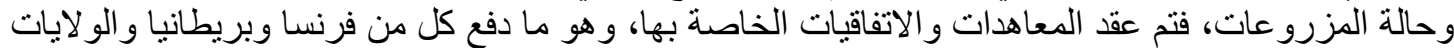
المتحدة الأمريكية إلى إصدار العديد من القو انين لعلاج هذه الظاهرة.

\section{التحليل الاقتصادي لتفتين التثغيرات البيئية}

للحماية القانونية للتغيرات البيئية أهمية اقتصادية للمجتمع، تتمثل في آثار اقتصادية جعلت هنالك حاجة إلى الى القيات

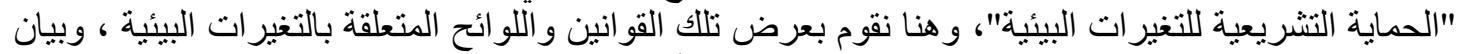

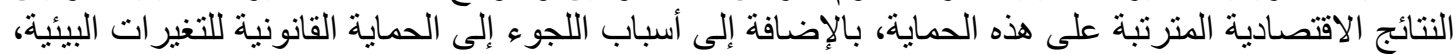

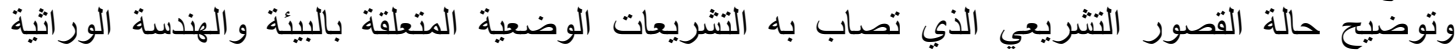

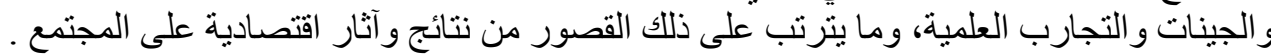

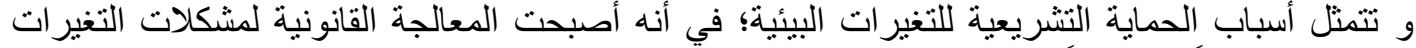

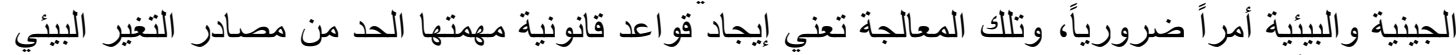

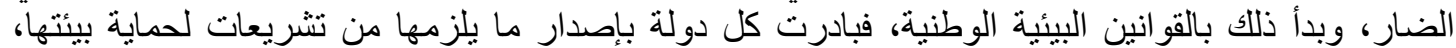

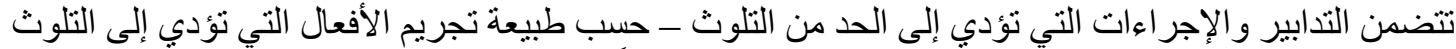

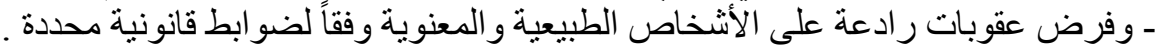

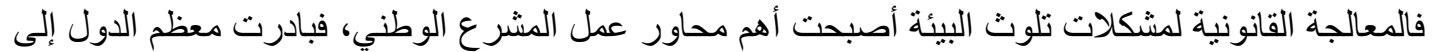

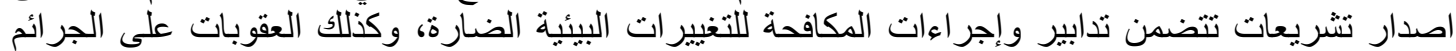




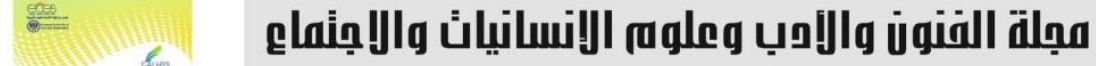 \\ Journal of Arts, Literature, Humanities and Social Sciences \\ www.jalhss.com

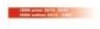 \\ Volume (68) June 2021 \\ العدد (68) يونيو 2021

ومن أجل تلك الأسباب فقد ظهر "قانون البيئة" رقم 4 لسنة 1994 نتيجة التطور ات التي جرت في الو اقع في

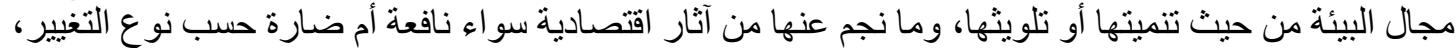

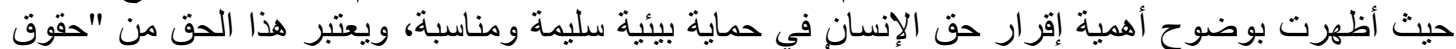

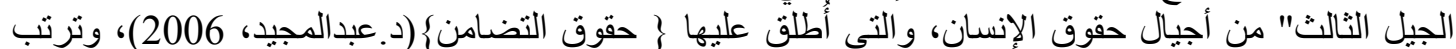

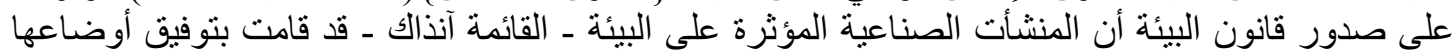

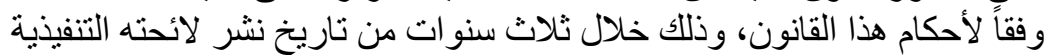

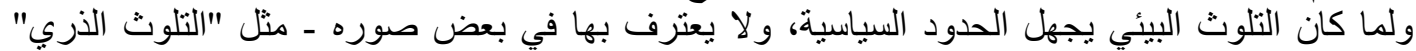

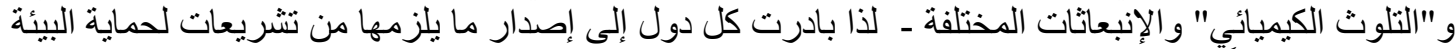

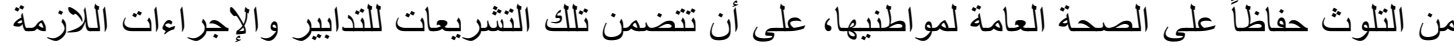

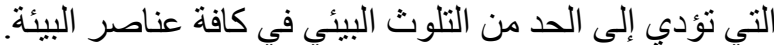
ومن منطلق أن حماية البيئة ليست مسئولية الدولة فقط ـ ـ ولكن يتحمل الأفراد و المجتمع الدولي جانباً كبيراً منها

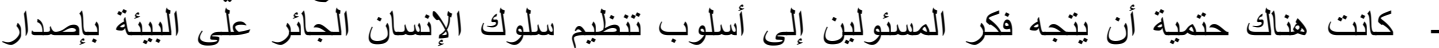

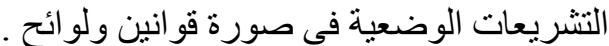

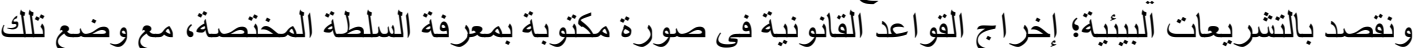

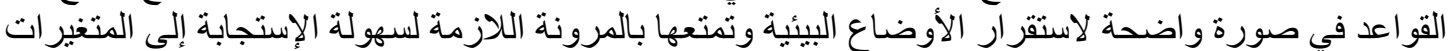

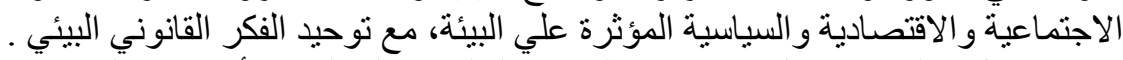

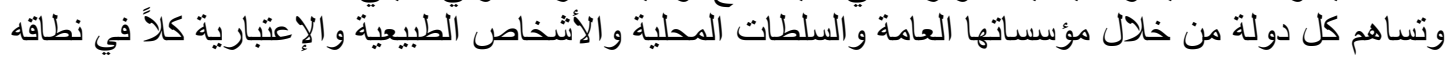

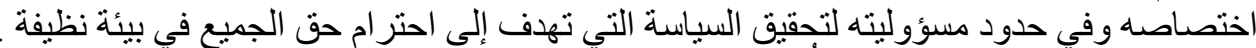

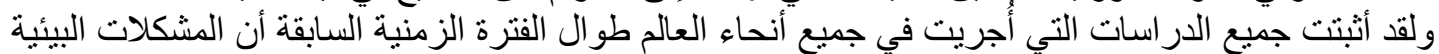

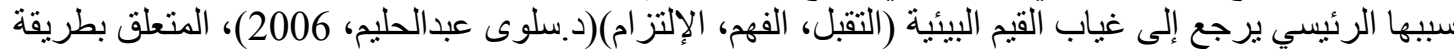

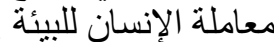

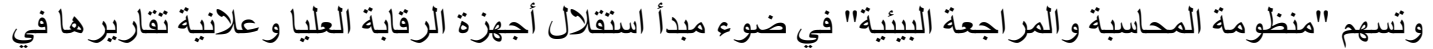

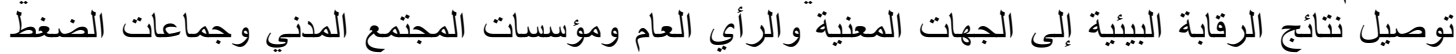

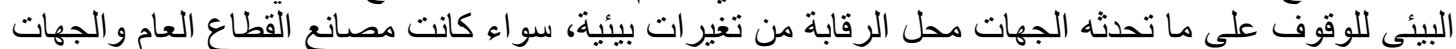

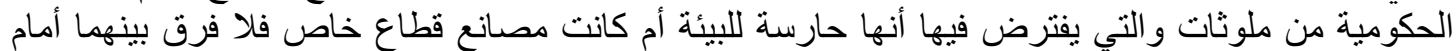

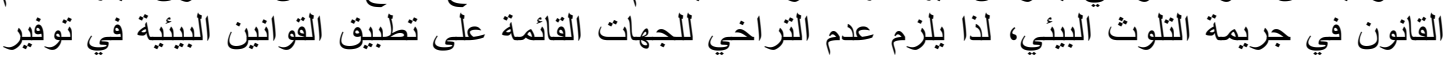

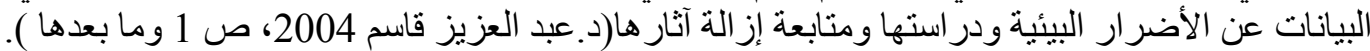

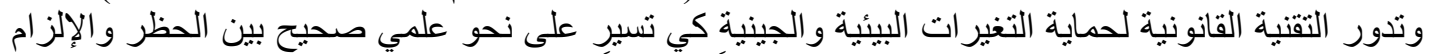

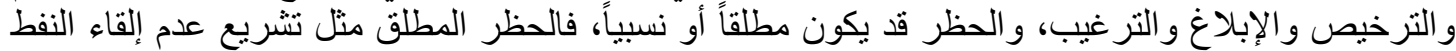

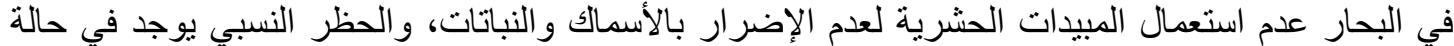

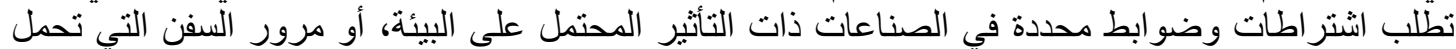

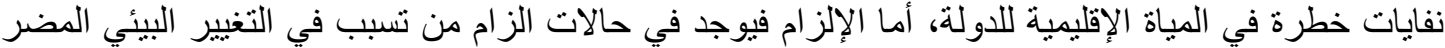

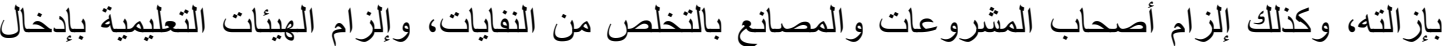

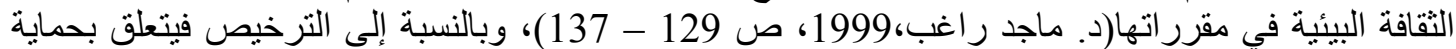

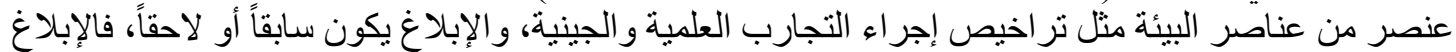

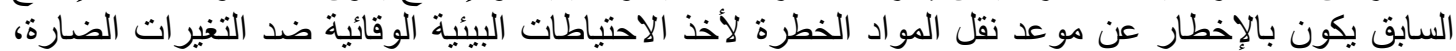

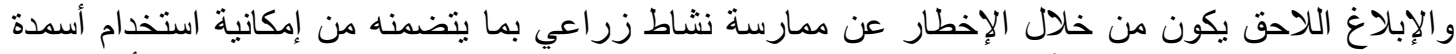

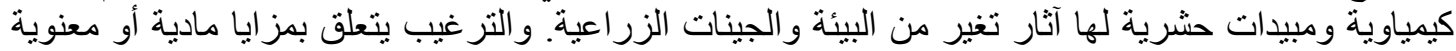

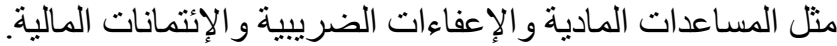

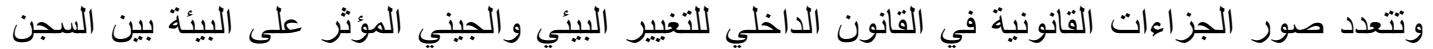

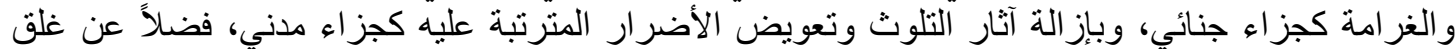

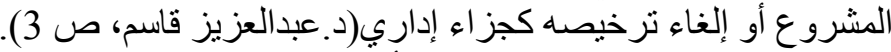

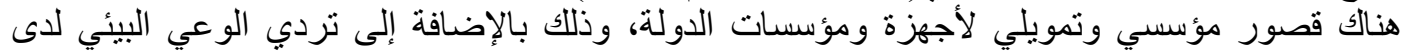
المو اطنين، وأمام هذا القصور السياسي و الاجتماعي؛ يصبح "التشريع" هو الأداة لتحقيق أهداف المجتمع في بيئة التئة 


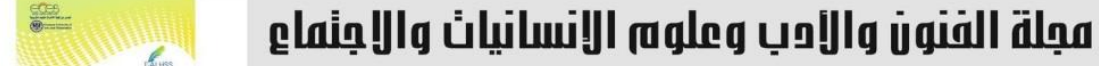 \\ Journal of Arts, Literature, Humanities and Social Sciences www.jalhss.com

أفضل، و إن لم يصاحب التشريع تطبيق جيد والتز ام فعلي متو افق مع طاقات المخاطبين بأحكامه فإنه يصير أداة

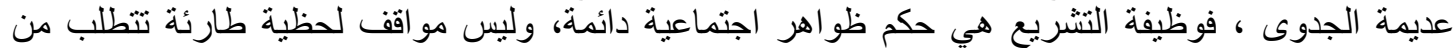

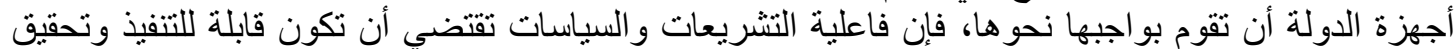

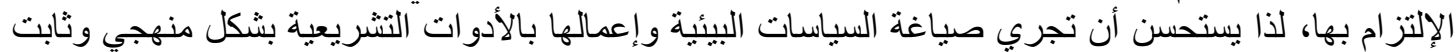

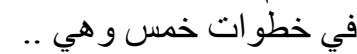

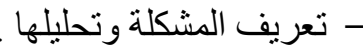

- اختيار الحلول المناسبة وأدو ات تنفيذها، مع ملاحظة أن أفضل تقنية متاحة لا تنطوي على كلفة مفرطة. - تحديد منظومة التنفيذ مثل التعامل مع المتغير ات البيئية و الجينية ومعالجتها.

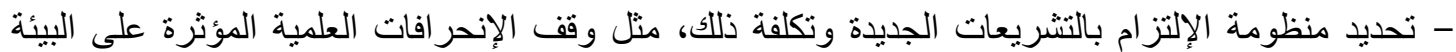

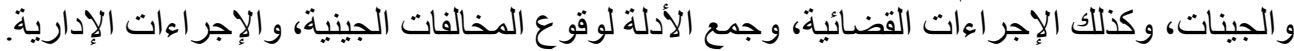

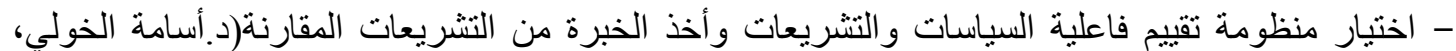

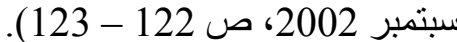
و التشريع لابد وأن يكون ترجمة للخصائص الجغر افية و الاقتصادية والسياسية للاولة، وقد تعددت التشريعات

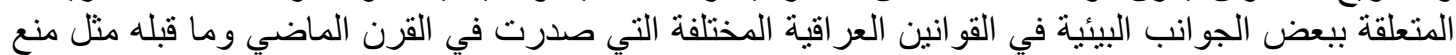

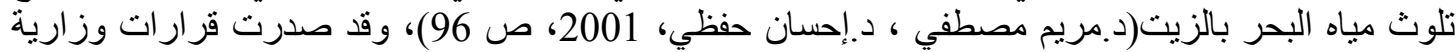

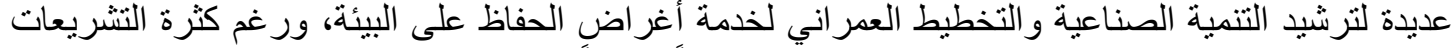

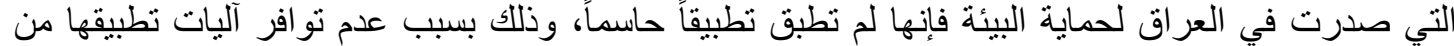

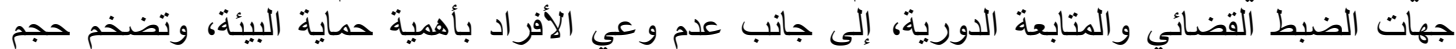

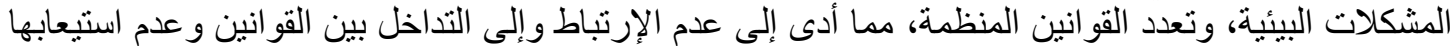
من قِبل الثخص العادي(د. أسامة الخولي، ص الثطنة 115).

\section{الأثر الاقتصادي للحماية الدوليّة للتغيرات البيئية}

يعتبر "القانون الدولي للبيئة" حديث النشأة، إذ أن أصوله الحقيقية تعود إلى نهاية الستينات من القرن الميلادي القياء

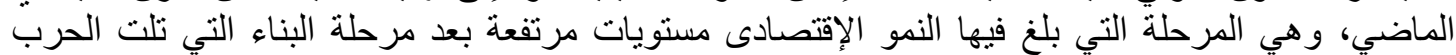

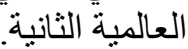
ويُعد قانون البيئة أحد أفرع القانون الدولي العام الذي يهتم بحماية البيئة بمختلف جوانبها، ويمكن إجمال

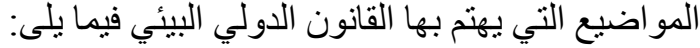
- منع تلوث المباه البحرية ، وتوفير الحماية والإستخدام المعقول للتروات والأحباء البحرية. - مماية المحيط الجوي من التلوث. - - حماية النباتات و الغابات و الحيو انات البرية. - مماية المخلوقات الفريدة.

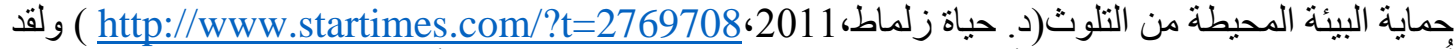
أبرمت مجمو عة من الإتفاقيات بشأن حماية البيئة، سو اء علئ على المستوى العالمي أم الإقليمي.

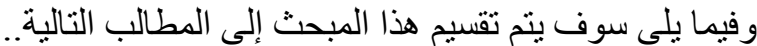
المطلب الأول.. العائد الاقتصادي لدور الاتفاقيات و المنظمات الدولية في حماية التغير ات البيئية. المطلب الثاني.. القو اعد الدولية لحماية التغير ات الجينية البيئية. . 


\begin{tabular}{|c|c|c|c|}
\hline 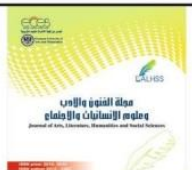 & 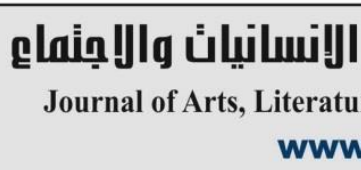 & 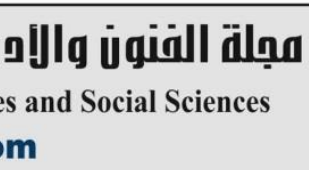 & \\
\hline$=\quad==$ & Volume (68) June 2021 & العدد (68) يونيو 2021 & \\
\hline
\end{tabular}

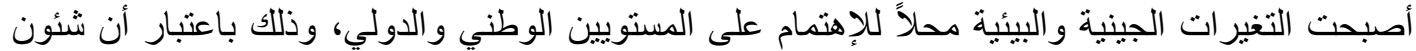

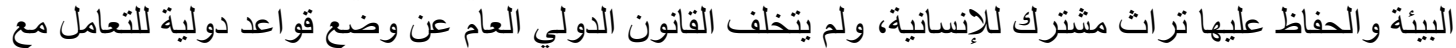

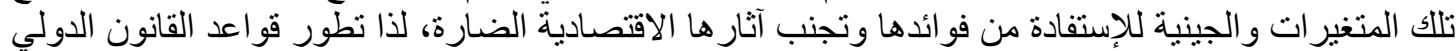

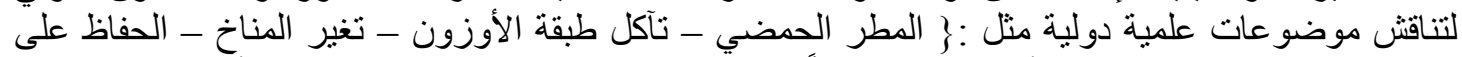

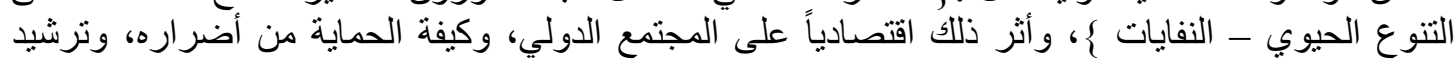

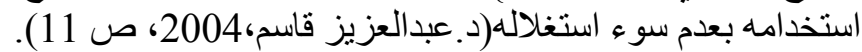

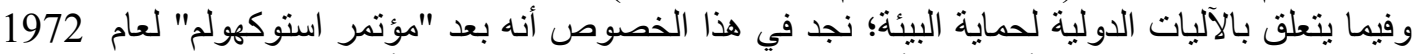

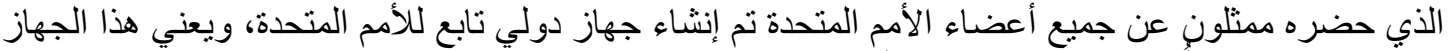

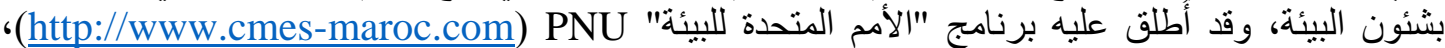

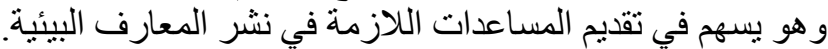
ولقد أدت العديد من الإتفاقيات إلى إنشاء بعض العضات المنظمات الدئة الدولية المتخصصة بتوفير آليات خاصة بقضايا

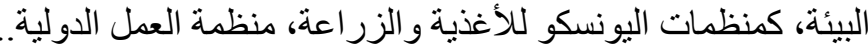

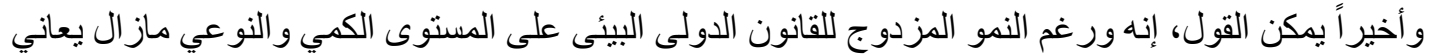

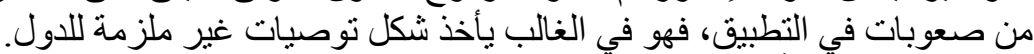

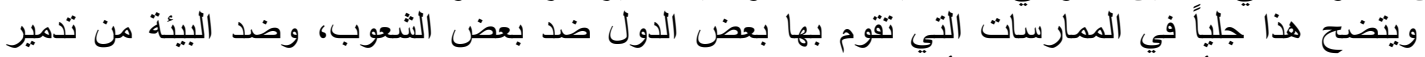

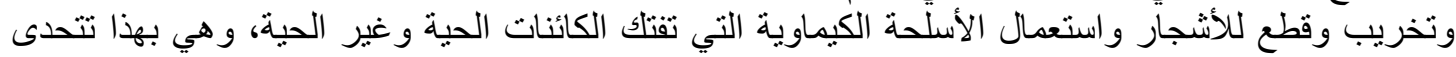
جميع القو انين الدولية المتعلقة بحماية البيئة وبحقوق الإنة الإنسان.

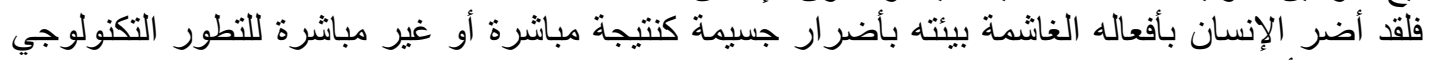

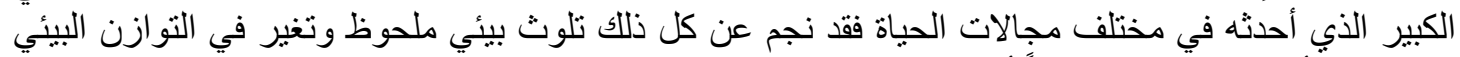

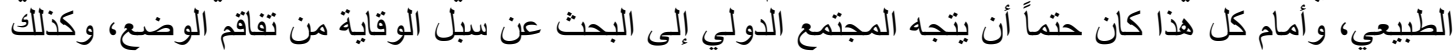

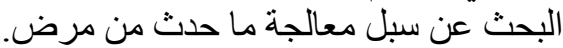

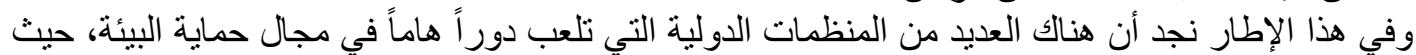

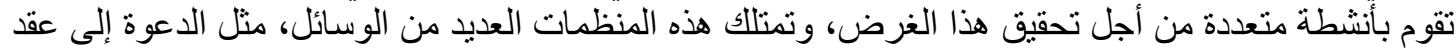

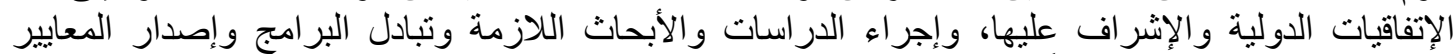

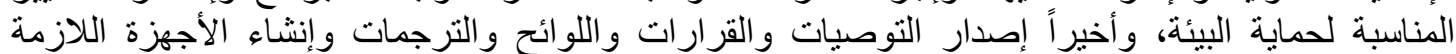
ل الذلك(د.

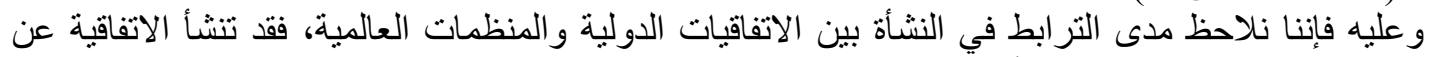

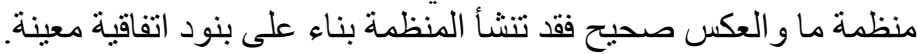
تتقسم الاتفاقيات المهتمة بشئون البيئة و التغيرات الطارئة علئة عليها بسبب التقنيات الجينية الحديثة والتكنولوجيا الجديدة إلى اتفاقيات عالمية وكذللك اتفاقيات إقليمية.

فعلى المستوى العالمي؛ كانت أهم الإتفاقيات المبرمة ما يلي ..

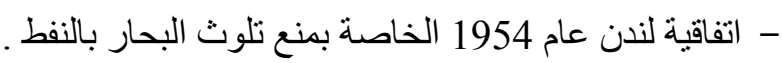

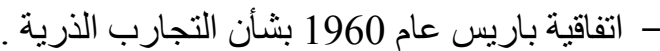

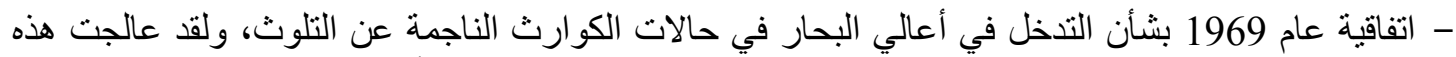

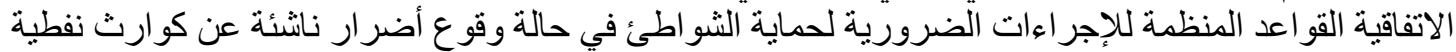

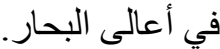
- اتفاقية "بروكسل" عام 1970 بشأن صيد وحماية الطيور.

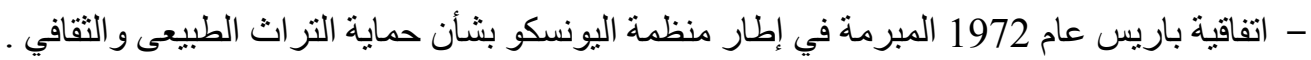

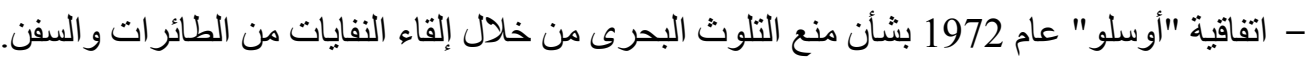




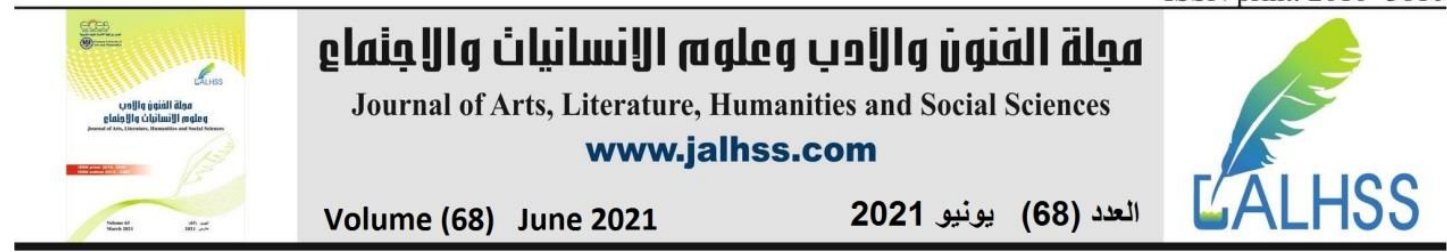

- الإعلان العالمي للبيئة في "استوكهولم" لعام 1972 ، وهو اللبنة الأولى في صرح القانون الدولي للبيئة

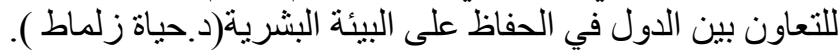

- اتفاقية واشنطن عام 1977 في إطار منظمة العمل الدولى بشأن حماية العمال من الأخطار الناجمة في بيئة العمل عن تلوث الهو اء و عن الضوضاء النواء وما شابه ذلك.

$$
\begin{aligned}
& \text { - الميثاق العالمي للطبيعة عام } 1980 . \\
& \text { - اتفاقية الأمم المتحدة لقانون البحار عام } 1982 . \\
& \text { - }
\end{aligned}
$$

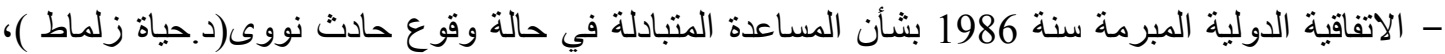

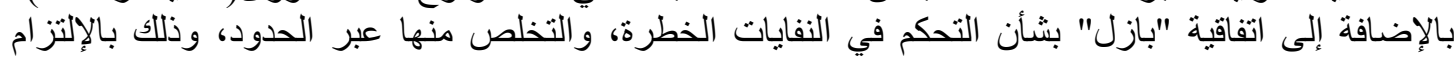

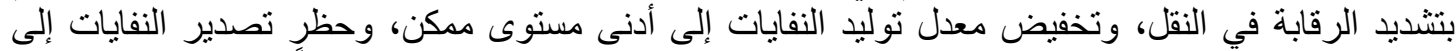

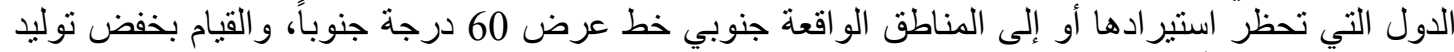

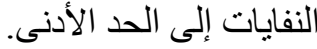

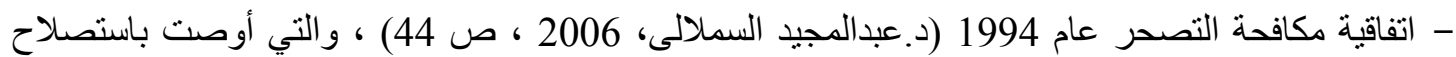

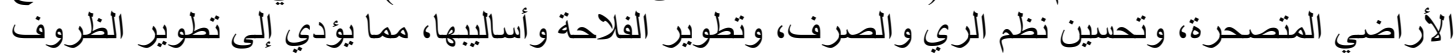

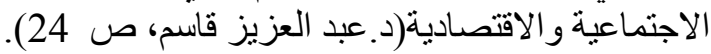

- بروتوكول طوكيو بتاريخ 16 مارس 1998، والذئى يلزم الدول المتقدمة بالحد من الأنشطة الاقتصادية

الضارة بالبيئة(www.cmes-maroc.com.

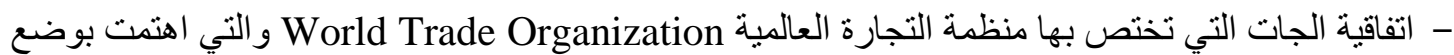

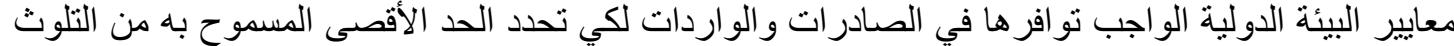

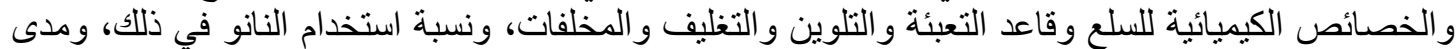

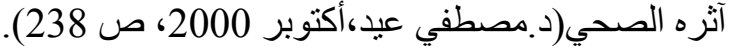
ولقد أخذت العديد من المنظمات الدولية المتخصصة على عاتقها مو اجهة الأضر ار البيئية، ومن هذه المنظمات

$$
\text { كلاً في سبيل المثاله : علئ . }
$$

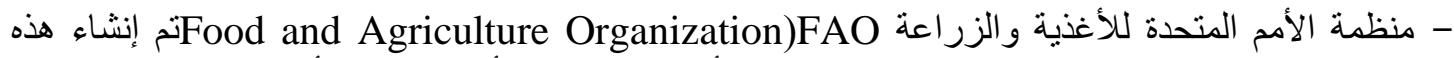

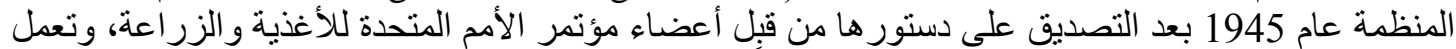
على رفع مستويات المعيشة ونوفير الإمدادت الغذائية للعالم).

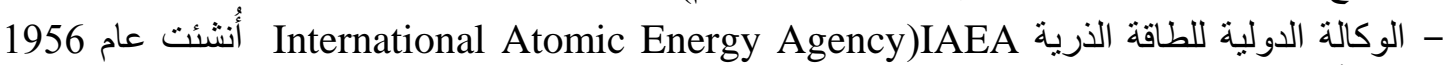

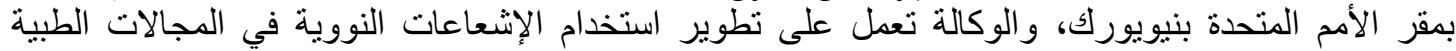

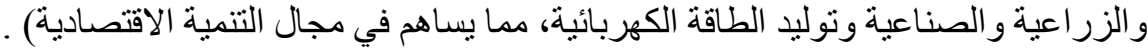

IMO: The International maritime organization known as )IMO المنظمة البحرية الدولية والية (intergovernmental consultive organization

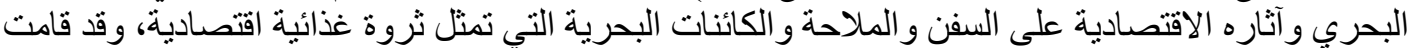

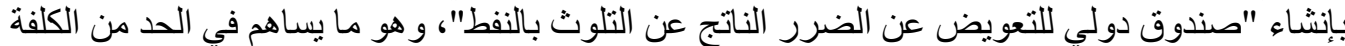

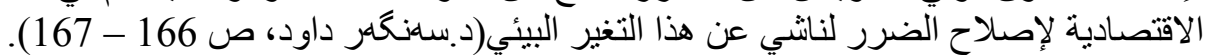

WHO: The world Health Organization is a specialized )WHO منظمة الصحة العالمية agency of the United nations that is concerned. Withe international public health it the who is a ' Sweitzer land،was established on 1april 1998 head quarter in Geneva the health 'member of United nations Development Group its predecessor ) وظهرت فكرة إنشاء تلك المنظمة خلال إعمال مؤتمر "سان فرانسيسكو" عام 1945م، وتمت الموافقة علي الإتفاقية المنشئة لهذه المنظمة 1946م، وقداء 


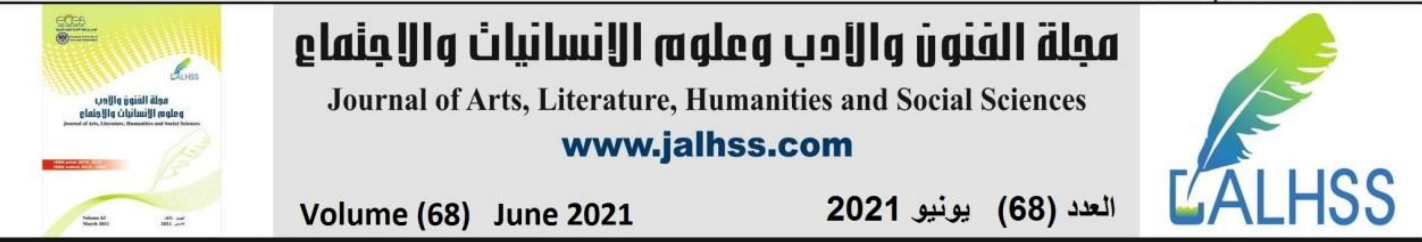

كان لمنظمة الصحة العالمبة دوراً فمّالاً كباقي المنظمات المتخصصة في حماية البيئة، حيث تقوم بتقبيم الآثار

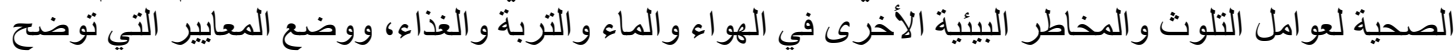

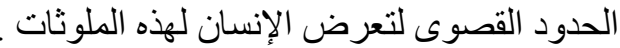

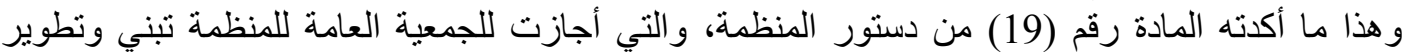

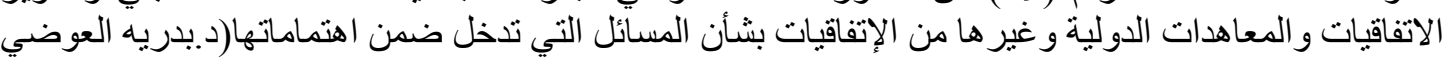

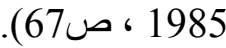

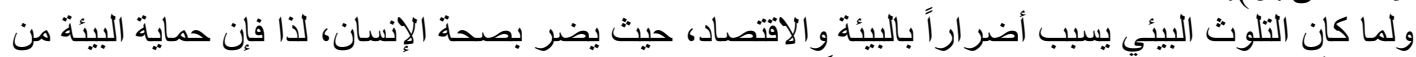

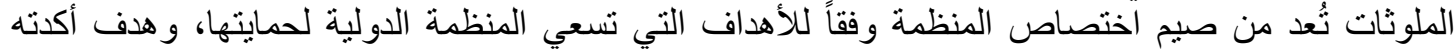

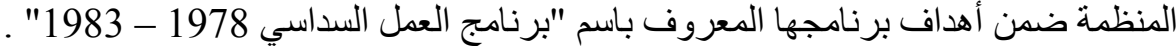

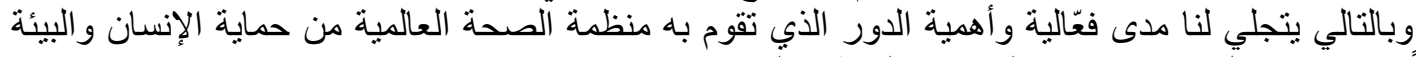

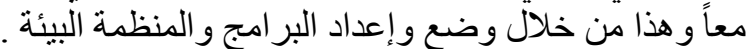

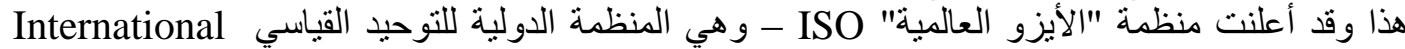
standardizations Organization

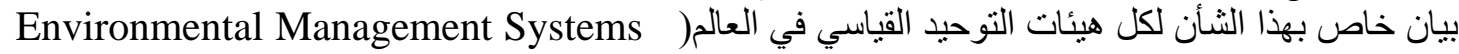
International ،JAPAN، (ISO) 14001،EMS) for Local Government Administration و و P1.، 2002،Cooperation Agency

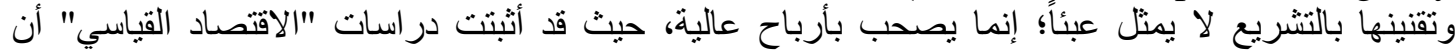

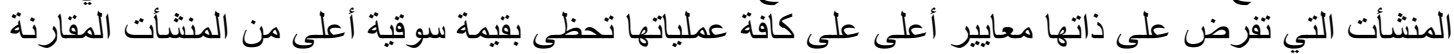

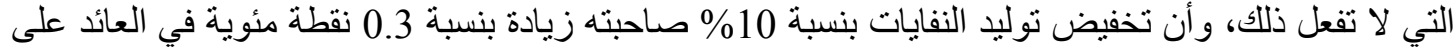

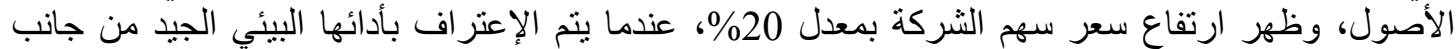

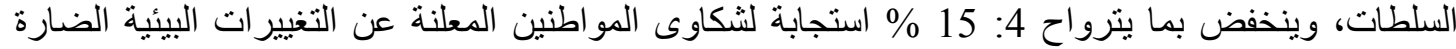

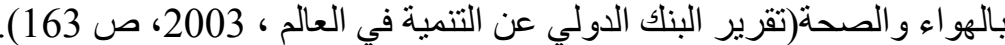

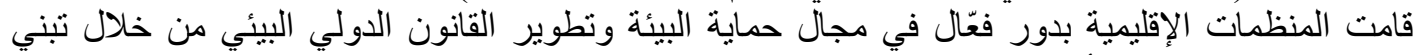

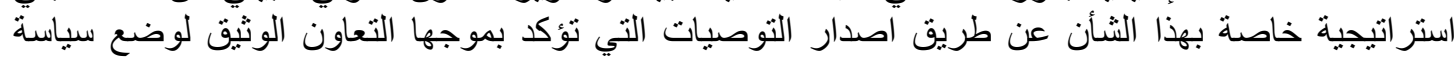

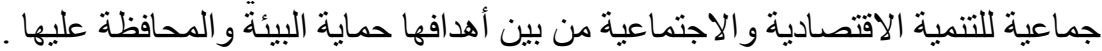

\section{القواعد الدولية لحماية التغير الثيات البيئية}

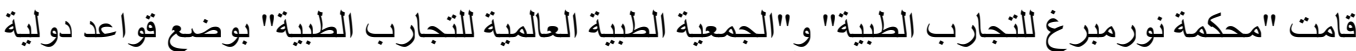

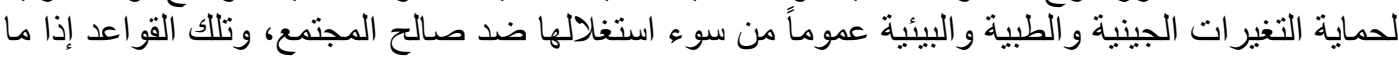
تم مر اعاتها فإنه سيكون لها أثار اقتصادية جيدة على البيئة .

وحديثنا عن تلك المحكمة والجمعية التي تختص بالتجارب الطبية يشمل في ذاته التجارب الجينية باعتبار ها

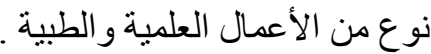

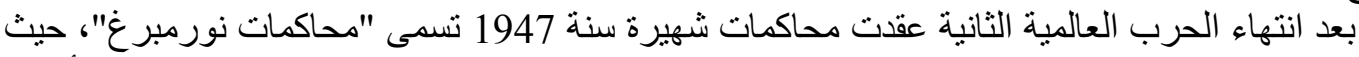

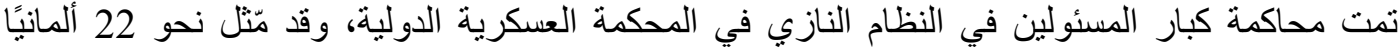

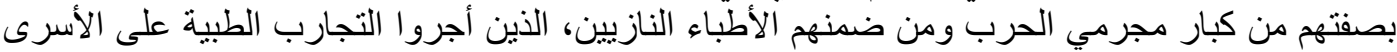

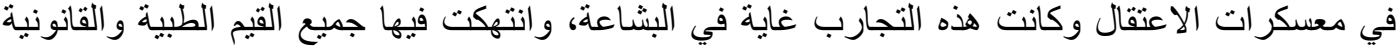

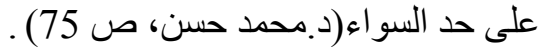

وقد أسفرت هذه المحاكمات عن وضع قو اعد قانونية وطبية تحكم إجر اء التجارب الطبية، بنو عيها العلاجية و غير العلاجية (العلمية)، والتي تجرى على البشر بصفة عامـة، بل ومن الأحرى تعميمها على كافة صنية صور 


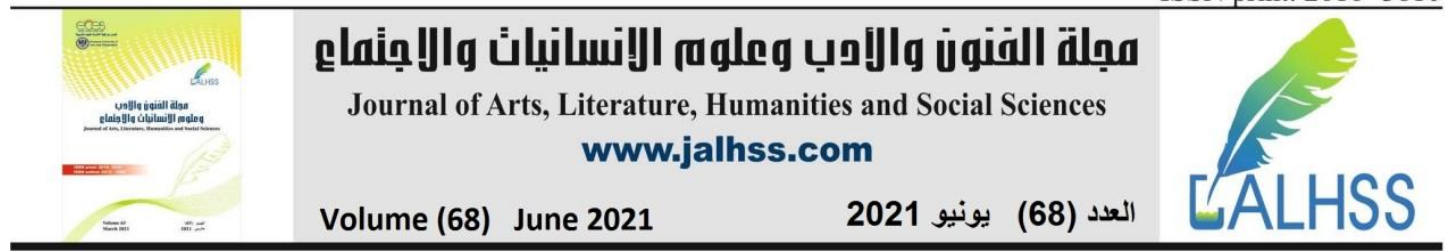

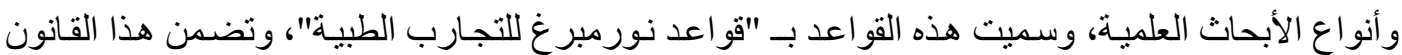

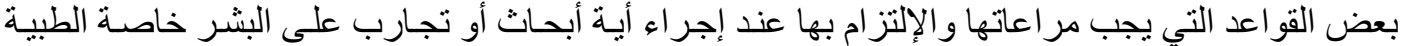

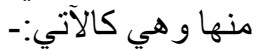

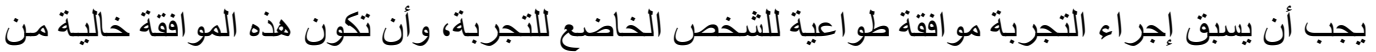

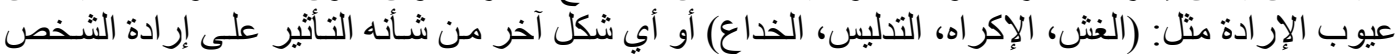

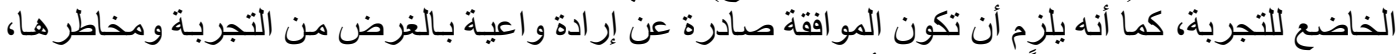

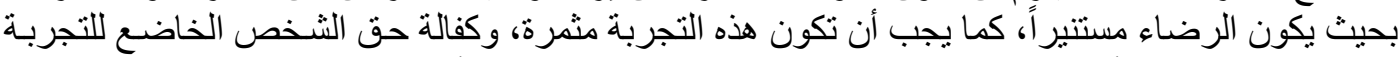

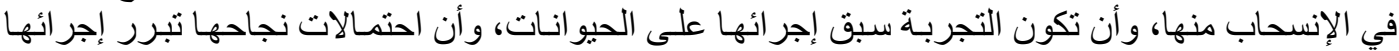

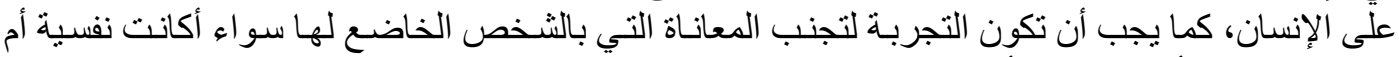

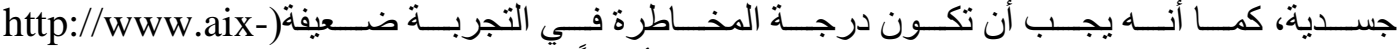

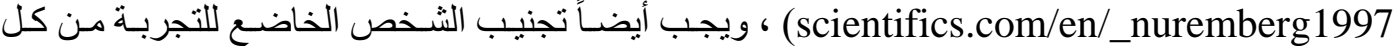
خطر محتمل مهما كان قليلاً قد يؤدي إلى إحداث جروح أو عجز أو وفاة(د.مرعي منصور ، ص 128).

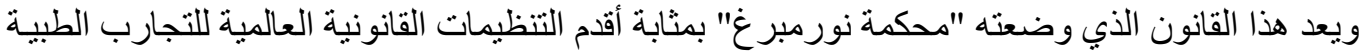

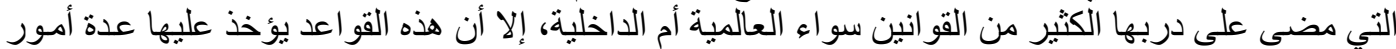

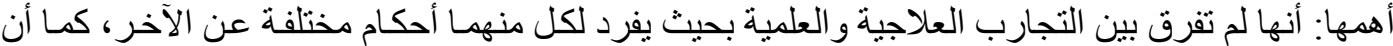

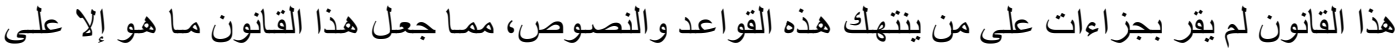

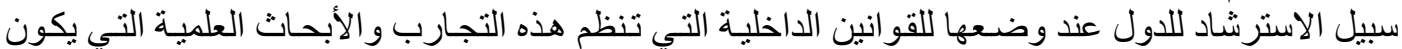

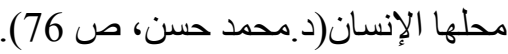

ولعل تللك القو اعد تمثل الحماية القانونية للتغير ات الجينية الناتجة عن التجارب و الأبحاث العلميـة والطبية،

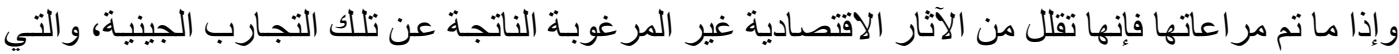

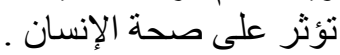

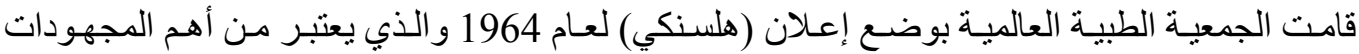

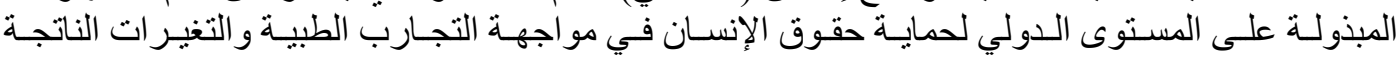
عنها (http://www.aix- scientifics.com/en/helsinkil1964.html)

الخاتمة

استعرضنا من خلال هذا البحث؛ ماهية "التغير ات البيئية"، و حيث أنه لبناء مجتمع معرفي في البلدان العربية

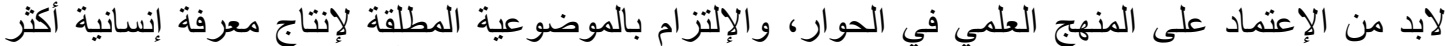

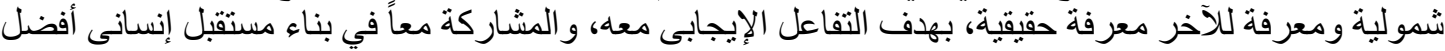
عبر تطوير نظام التعليم والبحث العلمى، وتبادل الخبرات الأكاديمية، وتنشيط الحوار التئنار الثقافي والمعرفي بين

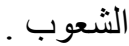
نحن نرى في الآونة الأخيرة اتساعاً علمياً شمل العديد من جوانب الحياة ، ومن المتوقع في الأعوام القادمة

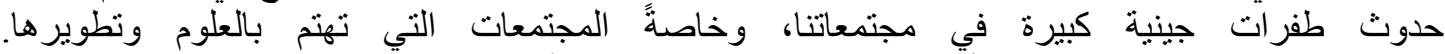

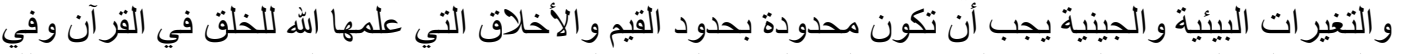

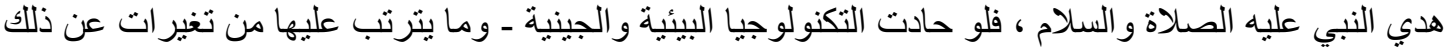
الطريق فلابد للفساد أن ينتشر.

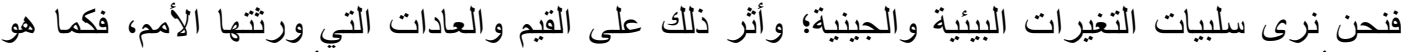

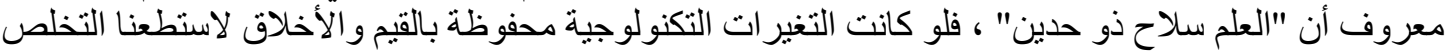

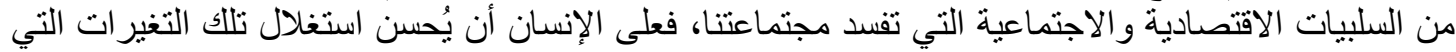

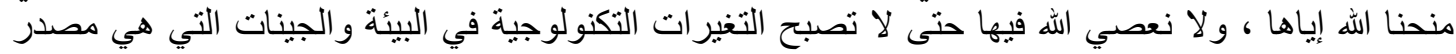




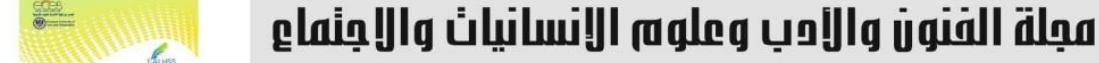 \\ Journal of Arts, Literature, Humanities and Social Sciences www.jalhss.com

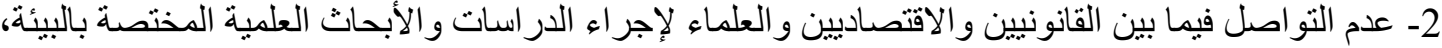

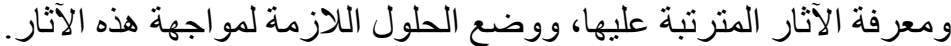

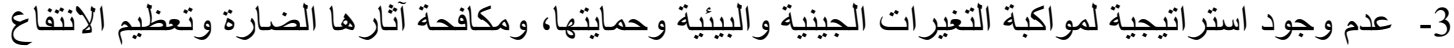
بآثار ها المفيدة للمجتمع.

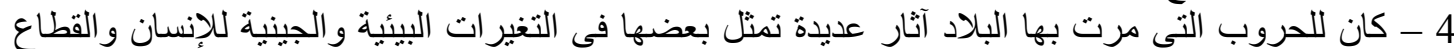
الزر اعي ومن ثم المجتمع عموماً، وخير شـاهد على ذلك ما حدث بمدينة "حلبجة" بالعر اق من استخدام للأسلحة

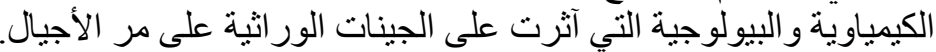

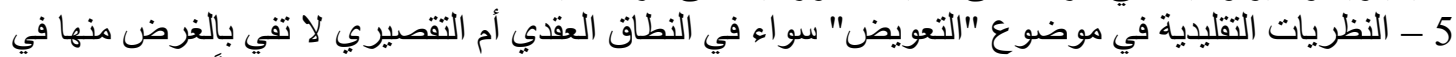

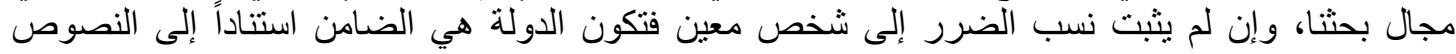
الاستورية والقانونية ومباديء وقئ حقوق الإنسان .

ـ تدبير الإعتمادات اللازمة لبرامج التغيرات البيئية والجينية، واعتبار التخطيط البيئي جزء من التخطيط

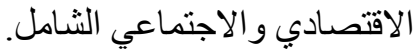

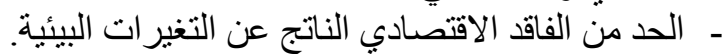

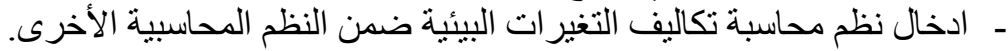

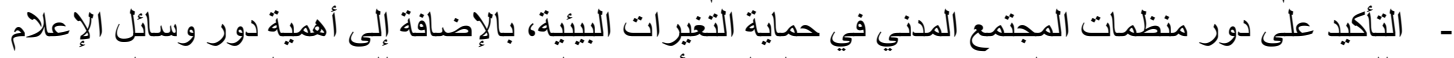

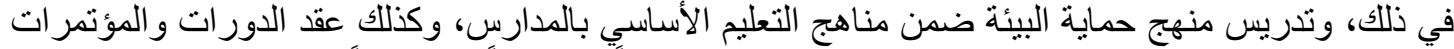

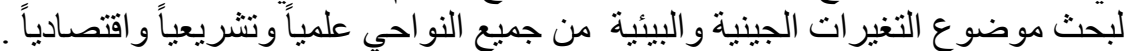
- ضرورة فرض "ضريبة التلوث" من قبِل المشرع على الصناعات والأنشطة ذات التأثثر البيئي، وذلك إعمالاً

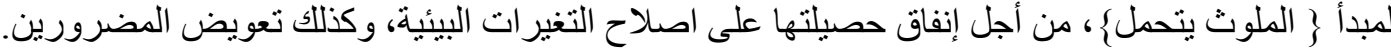

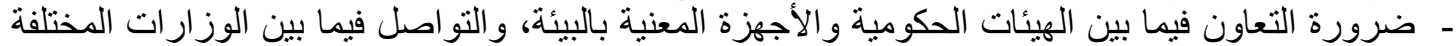

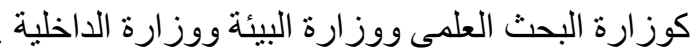

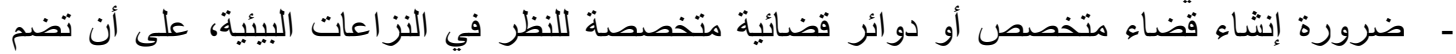

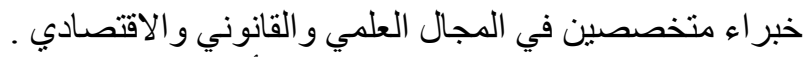

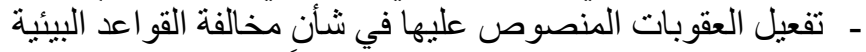

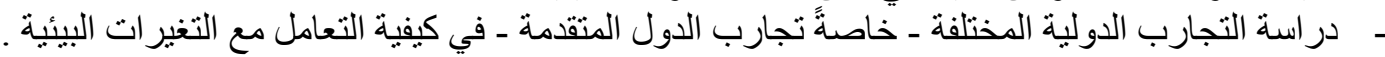




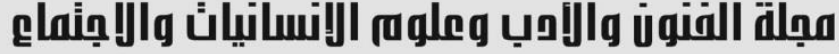

Journal of Arts, Literature, Humanities and Social Sciences www.jalhss.com

Volume (68) June 2021
العدد (68) يونيو 2021

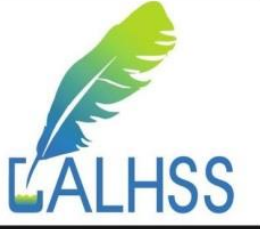

المصادر

1. http://www.aix- scientifics.com/en/helsinkil1964.html

2. http://www.aix-scientifics.com/en/_nuremberg1997-

3. http://www.cmes-maroc.com

4. http://www.startimes.com/?t=2769708.

5. www.cmes-maroc.com.

6. https://specialties.bayt.com

7. محارب، د.عبد العزيز قاسم. 2004، أهم الآثار الاقتصادية لمخالفة قو اعد حماية البيئة... وفعّالي الحلول

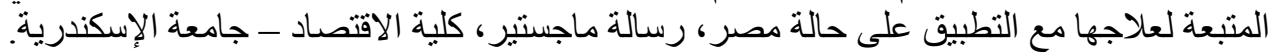

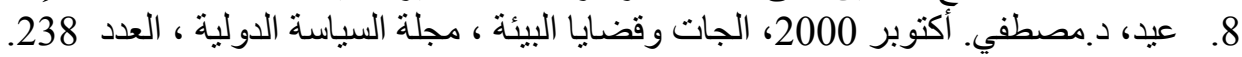

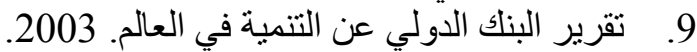

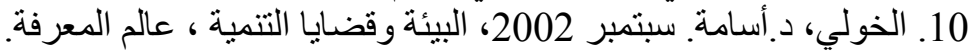

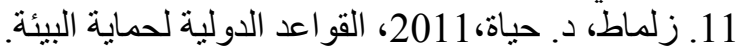

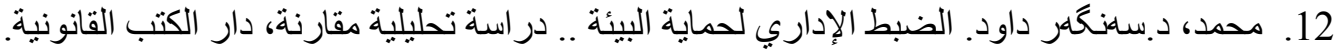

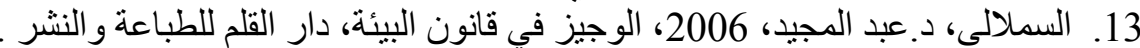

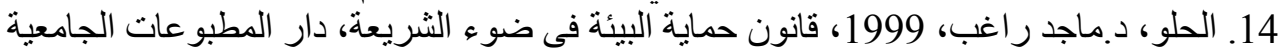
بالإسكندرية.

15. مصطفي، د.مريم و حفظي د.إحسان. 2001، قضايا التتمية في الدول النامية ، دار المعرفة الجامعة الإسكندرية.

16. العوضي، د.بدريه ـ 1985، دور المنظمات الدولية في تطوير القانون الدولي البيئي ، مجلة الحقوق الكويت.

17. نصار د.جابر جاد. 2000، مجلة اتحاد الجامعات العربية للاراسات والبحوث القومية، كلية الحقوق، جامعة القاهرة.

18. أبو العطا د.رياض. 2009، حماية البيئة في ضوء ع القانون الدولي ، دار الجامعة الجريدة ، القاهرة .

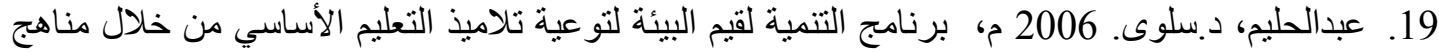

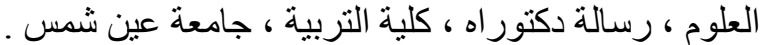
20. طر اف، د. عامر و حسنين، د.ميادة ـ 2012، المسئولية الدولية ولية والمدنية في قضايا البيئة و التتمية المستدامة

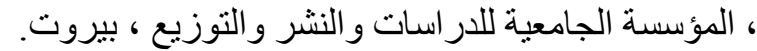

21. محمد، د.عبود سالم. 2011، مدخل إلى محاسبة التكاليف البيئية، جامعة بخداد، دار الدكتور للعلوم الإدارية و الاقتصادية.

22. الحلو، د. عقيل حميد جابر. لسنة 2013، بحث عن البيئة، منشور بمجلة القادسية للعلوم الادارية و الاقتصادية، المجلد (15)، دمديل العدد (1) .

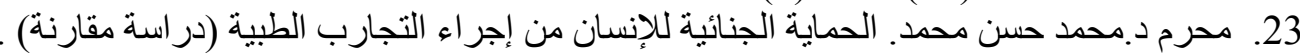

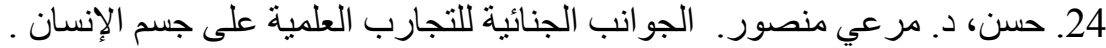

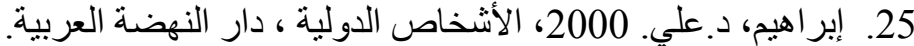

26. عبد الهادي، د.عبد العزيز مخيمر. 1986، دور الإنظمات الدولية في حماية البيئة، سلسلة دراسات قانونية للبيئة . 


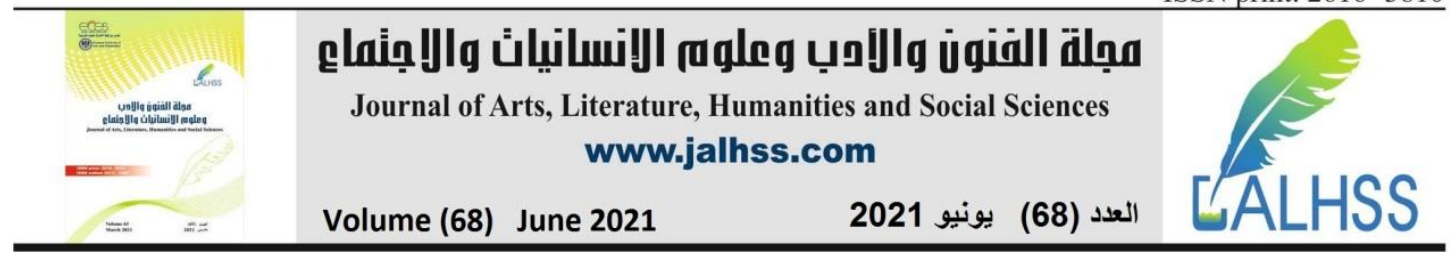

\section{References}

1. http: //www.aix- scientifics.com/en/helsinkil1964.html

2. http://www.aix-scientifics.com/en/_nuremberg1997-

3. http://www.cmes-maroc.com

4. http://www.startimes.com/?t=2769708.

5. www.cmes-maroc.com.

6. https://specialties.bayt.com

7. Muhareb, Dr. Abdulaziz Qasim. 2004, The most important economic effects of violating the rules of environmental protection ... and the effectiveness of solutions used to remedy it with application to the case of Egypt, Master Thesis, Faculty of Economics - Alexandria University.

8. Eid, Dr. Mustafa. October 2000, GATT and Environmental Issues, Journal of International Politics, Issue 238.

9. World Bank report on world development. 2003.

10. Al-Khouli, Dr. Osama. September 2002, Environment and Development Issues, A World of Knowledge.

11. Zalmat, Dr. Hayat, 2011, International Rules for Environmental Protection.

12. Muhammad, Dr. Singer Dawood. Administrative Control for Environmental Protection ... A Comparative Analytical Study, The Legal Book House.

13. Al-Samlali, Dr. Abdel-Majid, 2006, Al-Wajeez in Environmental Law, Dar AlQalam for Printing and Publishing.

14. Al-Helw, Dr. Majid Ragheb, 1999, Environmental Protection Law in the Light of Sharia, University Press, Alexandria.

15. Mustafa, Dr. Maryam and Hefzy, Dr. Ihsan. 2001, Development Issues in Developing Countries, University of Knowledge, Alexandria.

16. Al-Awadi, Dr. Badriya. 1985, The role of international organizations in the development of international environmental law, Journal of Law Kuwait.

17. Nassar Dr. Jaber Gad. 2000, Journal of the Association of Arab Universities for National Studies and Research, Faculty of Law, Cairo University.

18. Abu Al-Atta, Dr. Riyadh. 2009, Environmental Protection in Light of International Law, University House Al-Jarida, Cairo.

19. Abdel Halim, Dr. Salwa. 2006 AD, Development Program for Environmental Values to educate basic education pupils through science curricula, PhD Thesis, College of Education, Ain Shams University.

20. Tarraf, Dr. Amer and Hassanein, Dr. Mada. 2012, International and Civic Responsibility in Environmental and Sustainable Development Issues, University Foundation for Studies, Publishing and Distribution, Beirut.

21. Muhammad, Dr. Aboud Salem. 2011, Introduction to Environmental Cost Accounting, University of Baghdad, Dar Al-Doctor for Administrative and Economic Sciences.

22. Al-Helw, Dr. Aqeel Hamid Jaber. For the year 2013, a research on the environment, published in Al-Qadisiyah Journal of Administrative and Economic Sciences, Volume (15), Issue (1). 


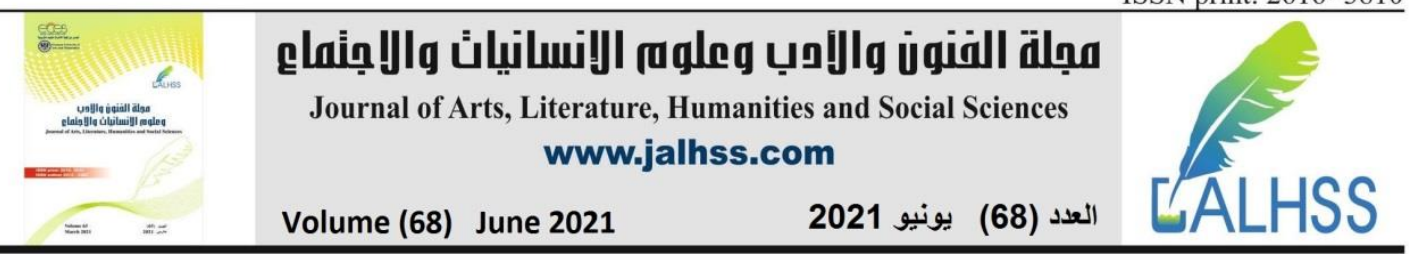

23. Muharram Dr. Muhammad Hassan Muhammad. Criminal protection of humans from conducting medical experiments (a comparative study).

24. Hassan, Dr. Mari Mansour. Forensic aspects of scientific experiments on the human body.

25. Ibrahim, Dr. Ali. 2000, International People, Arab Renaissance House.

26. Abdel-Hadi and Dr. Abdel-Aziz Mukhaimer. 1986, The Role of International Organizations in Environmental Protection, Environmental Legal Studies Series. 